\title{
Contemporary Water Landscapes. Trends, Issues and Techno-creation.
}

\author{
Sabina Kuc, Luidmila Ruban
}

\begin{abstract}
The studying of natural water landscapes has a lot of ways and methods. Especially, it became important nowadays when the newest technologies and ideas stay on the position of protection and renovation of nature environment.
\end{abstract}

The main definition of techno-creation and understanding of its place today were given in the first part of the paper.

The second part shows the meaning of Water from TechnoCreative point of view as we look towards the main constructive tendencies. Through analysing the modern European buildings and objects of landscape architecture the new approaches to usage of "water" in contemporary architecture have emerged. This analysis of modelling space with three states of water (solid, liquid and vapour) constitutes the cornerstone of the research. The main water's shapes and forms are studied.

The third part is dedicated to the further parallel development processes that could appear in modern architectural and landscape practice, which is strongly connected with water usage. In this field the trends of usage of water as the habitat environment may be investigated. Another approach can appear as a result of determination for the role and throughout discussing the challenges of landscape water objects in modern architectural practice.

Keywords - landscape architecture; techno-creation; water; landscape water objects;

\section{INTRODUCTION}

This paper is devoted to extended discussion of issues previously raised by authors in publication "Water as Factor of Techno-creation", that have received the diploma "Best Paper Research" at ACE-2014, Singapore.

From one side, authors decided to depict in more details some theoretical aspects of Techno-creation. In addition, a number of new issues are considered as going deeper disclosure of the subject of water in modern landscape architecture.

In the contemporary world there is a progressive process of technicisation in both the inner and outer world of man. Already in the nineteenth century Samuel Butler defined the technology as: "an extension of a human being, more or less distant senses, limbs or intellect which enhance inborn abilities. Technology, being an extension of the brain, is becoming an integral, internal part of the human environment these days." Currently, one of the main activities undertaken by man, whose effect provides constant development, is the desire to create and improve the surrounding space. In this process, both the creator - the individual, and the object of creation - space, are influenced by technology becoming the subject of various technological processes.

History of mankind shows that this is the late twentieth century and early twenty-first century that is the period of rapid development. It is characterised by an increased pace of development in all areas of life. The main factor enabling the occurrence of these processes in different scientific disciplines is primarily the use of the latest achievements of technology and modern materials. Descriptions of the use of various new technologies have started to include more frequently the prefix "techno" which was combined with the terms of things or phenomena from different fields of human activity, either colloquial or to scientific language. Besides the great popularity of the word technology, which denotes a method of doing something, "techno" defines also the priorities of modern human endeavor in realizing the permanent needs of the human biology, and is being created as well by the constant development of techniques participating in the progress of civilization around him. Those techniques appear as a result of evolutionary changes in his psyche and current environmental influences.

The part II is devoted to research conducted at Cracow University of Technology, Poland, the parts III.B, IV - are devoted to research, conducted at KNUCA, Ukraine and the sections I, III.A, III.C, V - were prepared in joint research.

\section{TECHNO-CREATION AS THE STYLE OF} CONTEMPORARY LANDSCAPE ARCHITECTURE

\section{A. The essence of the techno-creation}

Today's ubiquitous techno-creation based on the fascination toward the latest technology becomes the basis for the activities of the contemporary world. It manifests itself through the feedback of two phenomena - technology and creation, which both generate integral and distinguishing features of the created work. In a nutshell, techno-creation is $[1,2,3,4,5,6,7]$ : the process of creative thinking itself (including inspiration and reception); the physical manufacturing of new values in different areas of life 
inspired by the use of modern techniques and technologies; conducting research in the field of new materials (plastics); techniques and technologies; stimulating their development.
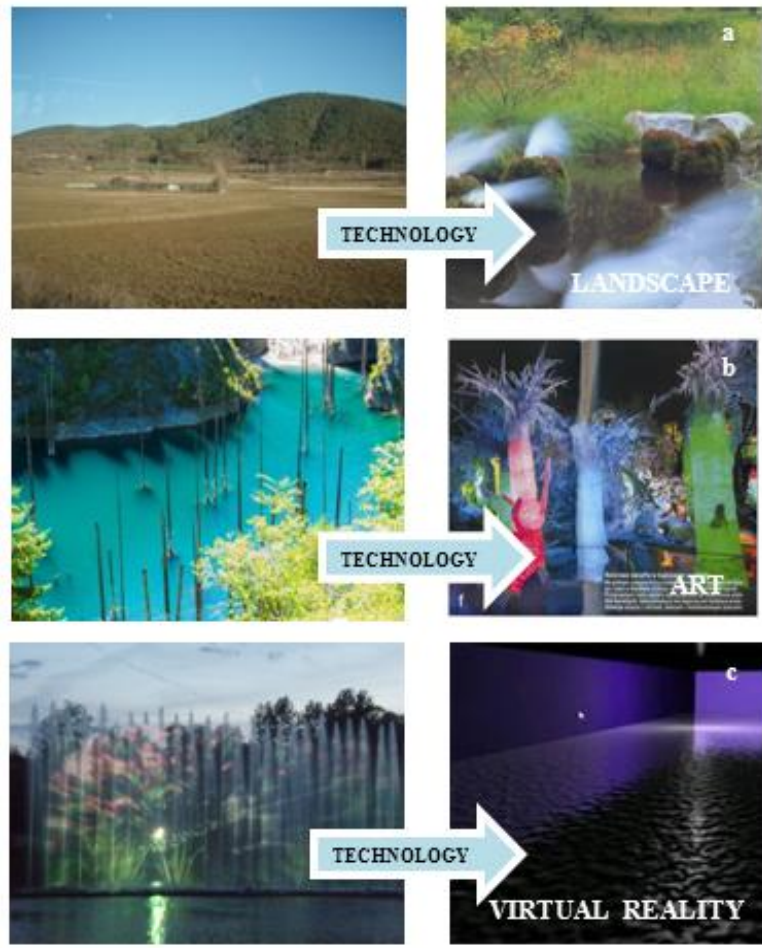

Figure 1. Defining the notion of techno-creation on the example of water [7]. (a. A meadow - an example of a landscape; The Spirit of the Place, authors: Julia Toll, Thomas Nordstrom \& Annika Oskarsson (The Puffing Mosses), Sweden Thomas Nordstrom, Annika Oskarsson, "Puffing moses", Stockholm, ([after:] [10] p.50.) - landscape shaped with the application of the latest building technologies; $b$. A forest in a water, Kaindy Lake, Kazakhstan ( phot.W.Kuc) - an example of a landscape; Exotic garden, ice transparency used for creating colourful effects; "The Second Harbin Ice and Snow World" - Competition for structures of snow and ice, one of the world's largest ice architecture parks, Harbin, China, ([after:] [11] p. 91.) - an artistic installation with ice; c. A system of multimedia fountains, Vinnitsa, Ukraine (phot. L.Ruban); an example from the virtual world.)

These activities are having a great influence on the formation of new trends in the development of contemporary and creation of the human environment. This allows for the creation of new either aesthetic or utilitarian values. One is inspired by the "old" and creates a contemporary new space through the use of the latest techniques and technologies. Design and implementation of bold innovative concepts in the field of techno-creation can activate several interrelated scientific and technical areas.

Modern techniques and technologies, in conjunction with an appropriately chosen thinking technique, allow the architect to create new aesthetic and utilitarian values. Let alone the work, in the process of creation one receives also the aesthetic values which shape both the creator and the recipient. This also applies to landscape architecture where we can discuss the cause- and effect-relationship commence simultaneously with the formation of the creator and the recipient in the process of programming and design of different types of space (interior $-\mathrm{a}$ building and exterior $-\mathrm{a}$ landscape)- which all gives the collection of ready-made forms.

It has been noticed that among the factors supporting techno-creative experiments in landscape architecture there are some additional benefits like: technical innovations (engineering), the freedom to create and receive (democratization of art), public demand for a shocking phenomenon (psychology, sociology) and the experimental creation of new spatial forms (expansion of civilization) [6].

\section{B. Techno-creation as a concept of the landscape organizatios}

Inoculation of techno-creational approach in landscaping can be related to developing trends in others than architecture areas.

As giving an example of different approaches in the use of technical progress in the implementation of architect it can be raised the figure of artists whose free thoughts can lead to both the formation of real-world landscapes and the creation of their virtual forms.

Among the many trends we can identify three modes of understanding the techno-creation in landscape architecture. In real space it can be: either an object of landscape architecture understood as the work implemented and maintained in proper condition using a variety of techniquesfrom gardening, land reclamation through construction, advanced lighting techniques to the creation of an artificial substratum, microclimate and architectural encasements, or an object of art (artistic installation),- as part of a larger architectural and scenic setting inspired by the world of technology or where the artifacts are the primary material used to create space in the landscape (illusions of nature, etc.). In virtual spaceit can be an object of landscape architecture implemented in a virtual landscape as a work of computer technology.

Among real landscapes one can find both restored and revived ones as well as those "created" as new in open or closed spaces. This group also includes spaces designed from the non-plant material - i.e. "artificial" landscape material. Their reception occurs naturally in situ by direct sensory perception. The situation looks different in the case of virtual landscapes. Modeled and stored in digital processes, they can be exposed through any multimedia techniques.

Landscapes can be composed by the authors from a variety of materials. One can use natural materials - plant and non-plant ones (building materials such as sand and stone in the form of blocks, plates or aggregates, sand or water, fog, ice) and artificial materials - man-made, e.g. construction materials (glass, plastics, metals, concrete) or other: paint, chocolate, other groceries (vegetables, fruits, meat products, etc.) paper, light. To create landscapes one can also use virtual materials that have no counterpart in the real space or being a virtual copy of real materials.

Projecting directly on the processes of techno-creation of a landscape contemporary techniques and technologies determine their visual qualities, spatial shape, functionality and utilisation economics. In the landscape techniques and 
technologies can be used as: the background - the setting, frames, covering; enclosures of landscape's interior; exposed - the rightful architectural material of visible elements and invisible to the eye - structure, substratym assisted in the creation and nurturing processes. Technologies which can be applied here include agrarian and construction technologies (combining building constructions with a plant material, green walls, green roofs, strengthened slopes, earth constructions), painterly (optical illusions, staffage, reflective anamorphosis - drawings on the walls and floors), sculptural (making sculptures of various materials, e.g. sand, ice, glass), multimedia (light, vibrations, sound, video and other special effects) and virtual ones - virtual reality (software of varying degrees of sophistication), including the Internet (for distribution, presentation and communication) and hardware (from a single computer screen to high-speed communication systems and advanced simulators) $[1,2,3,4,5,6,7,8,9,10,11]$.

Using the previously mentioned materials and technology techno-creation can be realized by composing widely understood forms - through formal ideas materialized in the landscape due to the progress of technology and by obtaining forms previously difficult, to implement according due to the technical (engineering) limitations, with selected material and technological solutions and functions - due to in conection to the new possibilities in restoration of degraded landscapes, creating new features for gardens, for example, parts of intelligent buildings, with a rational and economical technical solutions - ensuring the safety of use, reliability and durability.

Activities related to development of form and function, bearing signs of creative experiments, are perceived as a confirmation of constituting a distinct trend in landscape architecture.

\section{Creating a Landscape with an "Artificial" Material in a Real and Virtual Space}

In the history of the art of gardening, there are quite a few of examples (e.g. traditional Japanese garden and contemporary modernist garden) where the spaces traditionally perceived as green (colloquial understanding of the terms: park, garden) were created from natural, but not plant material, in the form of stones, gravel, sand, water, etc. Similar trends are beginning to reactivate now, in the wake of exploration and innovation in landscaping. Currently, gardens where natural greenery becomes just an excuse and the created space is dominated by architectonic substance or artificial materials are becoming common phenomena.

Until recently, the only examples of man-made green spaces were monuments of garden art. Apart from places accessible to the public, such as parks or public gardens, one can also include here the ones commissioned by individuals around their private properties. They were made in diverse styles, usually dependent on the time of their creation such as the abovementioned traditional Japanese garden and contemporary modernist garden. Trees, shrubs and flowers played the main role there. Yet, other natural materials such as gravel, sand or water $[7,8,9]$ were also used.
It has been noticed that single elements or entire plant complexes are being replaced with compositions made through using different technologies. In these compositions there are different ratios between artificial and natural elements as well as between projected and existing elements. These formations are composed of artificial plants, spatial forms inspired by plant forms and other element such as giant objects as well as internal and restrictive surfaces.

For inspiration-experimental systems most commonly used in the creation of "artificial" landscape one can include leaves, fruits or seeds together with whole trees and plants. To create such a landscape one can use, for example, the core of dead trees onto which modern materials molded into various shapes are applied. Withered plants can be an inspiration in themselves. An example would be a composition of "the tree with its roots upside down" established in Wroclaw. Using these ideas as inspiration can be helpful in creating various types of support frames for happenings, just like stands for billboards. One can also encounter various objects and textures to vary the composition. This kind of inspiration includes a composition "White Aviary" which has used a grid, or an installation "The Wrapped Trees" by Ch. Jawaszewa created with a fabric. A wide range of "material" can be chosen , from traditional and solid ones, such as metal or steel, to the ones which are characterized by a much shorter durability - e.g. paper strips or water in different states.

The replacement of plant components through forms resembling them but formed in the non-plant material has also become popular $[1,2,3,4,5]$. For example, the form of trees or their parts are made in various materials, mainly as steel and concrete constructions. Hence, there are tree lamps, trees from traffic lights or woody forms serving as a spray robot during the day and illuminating through the solar battery at night, as well as prototypes of artificial trees that can remove carbon dioxide from the air or supply composite materials or alloys with a given composition. The most spectacular is the creation of installations using materials from landfills or otherwise, waste (residues) of civilized life. There appear meadows "blooming" with CDs or glass multicolored pinnacles, "vegetation plains" with glass bottles, there are "field of lightning" growing - flowerbeds with six-meter rods of stainless steel, etc. Lamps in the shape of pumpkins, gourds, onions appear in green spaces. Trees or their fragments have inspired fencings, roofings and coverings. The appearance of these structures relate in varying degrees to the originals, resembling boughs or connected crowns.

There have been some attempts, inspired by the potential of nanotechnology to create artificial pseudo-trees growing at landfill sites. Suggestions for broadcasting views and sounds of nature by transmitting them on the Internet or creating virtual landscapes may become the domain of the future.

Another trend of experimentation in a landscape is the introduction of elements of supernatural size taken from the natural world or everyday objects $[1,2,3,4,5]$. Chairs, tables, cutlery, parts of the human body (head, hand or feet) and animals appear as sculptures or installations. Not only their 
size and the materials from which they are made are different from those that we are used to see but also their symbolic meaning differs. A silhouette of a man occupies a prominent place in the sphere of constant exploration of means of expression, it is used in green spaces in both the symbolic and naturalistic aspect to create a diverse composition in terms of scale and expression. The form of the human body is also used to create compositions in different spatial scales and materials.

In an era of rapid change, not omitting the latest trends in the design of landscapes, constitution of another architectural area of creative exploration in the form of cyberspace and designers' interest in miniaturization, microelectronics, multi and hyper-media and virtual reality has become obvious. Hence, more and more often one sees an escape from reality and the quest for beauty in the virtual space. The aim of such activities may be not only to create substitutes for reality, but, most of all, the parallel spatial dimension with a virtual environment where virtual rules of the game will apply. Many rules of the real world will probably have to be rejected in order to achieve an attractive performance.

Since the virtual space is the environment $[1,2,3,5]$ from which we expect the implementation of the impossible, it seems that the next stage and field for the activeness of the designers of green spaces will be design in the virtual form, in a form which is not only the visualization of an object or an electronic record of the project, but the experience of the place, form and perception. Therefore, virtual architecture may become an attempt to realize ideas and concepts which are difficult to implement in the real world, and the electronic environment is ideal for every, even the boldest experiment.

There are also other aspects of the use of computer technology in the presentation of projects. Projects - files can be shared over the network, i.e. wander in a virtual environment (it can be referred both to virtual designs and virtual architecture), they may be compressed in algorithmic codes and sent to various places of fabrication or roam in a virtual environment in a variety of configurations, while a file saved somewhere on your server can also be downloaded and read in many places in the world. Tele-topology (Virilio) is a fact, teleportation, i.e. moving at the speed of light (a SF term) takes on the hue of probability. The latest scanners enable us to replace spatial forms with digital records which can be sent to any place.

Finished products are subject to reception (perception) of the user. Previous experience of space is based on the physical, sensual experience of the surrounding world, but the same senses can provide experience and information about completely different dimensions of space. Virtual worlds, from the simplest animated designs to those facilitating broadly understood interaction, are becoming the object of perception.

We expect that virtual reality will generate a space whose properties would equal or even exceed nature. What matters is the perfection of recreation. As rightfull participants in the created environment we expect opportunities to travel and coexist in it on the basis of (interactive) feedback signals. We are also interested in the possibilities of transforming this world.

The mere passive interaction with virtual space, limited to visual perception only, is not enough. One needs reception with all their senses because man expects another attraction that will stimulate their senses. After all, although still imperfect, tactile simulators - VR helmets or glasses allowing the perception of the virtual space, are already in use. However, in relation to the expectations and vision for the future, they are only the forerunners of future technological possibilities.

\section{WATER AS THE IMPORTANT FACTOR OF CONTEMPORARY LANDSCAPE ARCHITECTURE [7]}

\section{A. Water and Techno-creation: coexistence's issues}

In scholars' opinion, it's very interesting to investigate the water from techno-creative point of view. The application of main statements of this theory on water investigation unleashes new directions of creative experiments and facilitates and opens the gates for new considerations of such natural substance, as water $[2,8,9]$.

Water is the key vital element to life in the Earth. It plays the great role in many aspects of human life, and in architecture and design as well. Architects, designers and, especially, landscape architects, always pay a special attention to water, as aesthetically all sufficient and decorative element of environment. At the end of $20^{\text {th }}$ century we have noticed the surge of professional interest to the "architecture of water" and this interest still continues unabated.

Through their impact on techno-philosophy and technothinking, contemporary techniques and technologies directly affect the processes of the techno-creation of a water determining its visual values but first and foremost its spatial shape, functionality and maintenance economics. In a landscape, water techniques and technologies can appear as [2]:

- $\quad$ invisible - the construction, background, support in the creating and nurturing process,

- $\quad$ exposed - the rightful water as a material of visible elements,

- the background - the setting, frames, coveringclosing of landscape enclosures,

- the background - the setting, frames, coveringclosing of landscape enclosures.

In such an environment of water as material, technocreation may proceed through the widely known composing of:

- the form: through formal ideas materialized in a landscape owing to technical progress as well as the creation of forms previously unfeasible on account of technical (engineering) limitations, i.e. by means of selected material and technological solutions, 
- the function: owing to the new possibilities of recreating degraded landscapes, creating new functions for gardens, e.g. as parts of intelligent buildings, with the application of rational and economical technical solutions guaranteeing safety and durability. the background - the setting, frames, covering-closing of landscape enclosures.

\section{B. Water as a Structural Material}

Recently emerged technologies of XXI century give us an opportunity to reconsider our attitude toward natural landscape component "water" as not only a decorative environmental element. Modern technologies show new possibilities of using water in construction - as a kind of constructive and creative material and as an informational carrier. Now it's time to discover and understand the possibilities of techno-creative usage of modern technologies on the example of water. For these purposes the three states of water - liquid, solid and vapour - were chosen as a departing point of the research $[6,7,12]$ and the attitude towards water as a natural constriction substance was set as the base.

The techno-creative usage of water in the form of vaporized water shell can be illustrated by the example of Blur Building - a temporary media pavilion built for Swiss Expo 2002 [10]. The authors of the idea - architects Elizabeth Diller and Ricardo Scofidio won the competition for the site in Yverdon with the idea of making an inhabitable cloud whirling above the water surface of the lake Neuchatel [16]. For this purposes water, like the primary construction material, pumped up from the lake below and emitted into the air by over 30,000 high pressure nozzles. A built-in weather station controls fog output in response to shifting climatic conditions such as temperature, humidity, wind direction, and wind speed. This fog created a manmade cloud that encompassed the metal framework to create

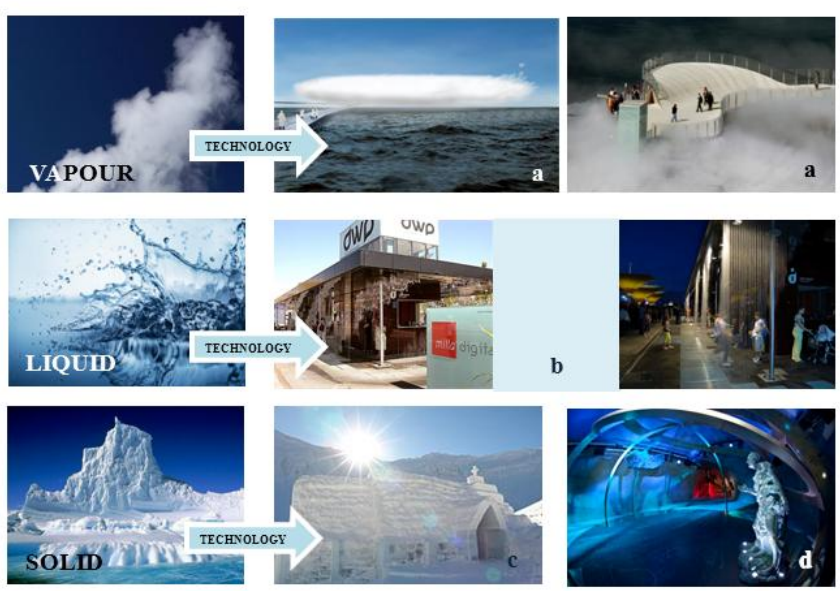

Figure 2. Water as a Primary Construction Material: (a. The Blur Building, computer sketch, Yverdon-les-Bains, Switzerland, 2002. Diller- Scofidio- Renfro. (phot. Diller and Scofidio); b. The Digital Water Pavilion- an entrance pavilion for EXPOAQUA, Zaragoza, Spain, 2008. MIT team of architects- Lumiartecnia Internacional. (phot. Lumiartecnia Internacional); d. The Ice Church in Romania, 2011; e. The Ice Palace, the Jungfrau, the Bernese Alps, Switzerland, since 1912.) the illusion of a vaporous building measuring $300 \mathrm{ft}$. wide and $65 \mathrm{ft}$. high [17].

Unfortunately, contrary to the Eiffel Tower, which was also initially build as an exhibition exponent and was lucky to left forever, this perception-altering exhibition was not built to be a permanent structure, and no longer exists.

Techno creative usage of the water in its liquid state is showed by Digital Water Pavilion (DWP) - the information point of Milla on Zaragoza World Expo 2008 in Spain [18]. The great combination of two extremely different themes old good water and modern digital technologies - was laid as the basic idea for this construction. DWP is an interactive structure made of digitally-controlled water curtains with exhibition area, tourist information centre and café inside. In deed this liquid building could be flexibly adopted and may easily transform its shape in accordance to frequently changeable people's needs. In such way the engineers from Massachusetts Institute of Technology (MIT) decided to achieve such previously unbelievable level of possible flexibility. It was a pioneering construction of its kind and illustrated the potential of digital water architecture in creating of dynamically transformable spaces. "The DWP is the first attempt to use water walls on the architectural scale. Moreover, in the DWP water walls are not used merely as a decoration. In fact, they are a key element in the creation of changeable spaces and they act as a medium of communication," said Matteo Lai, a member of the design team from architectural firm Carlo Ratti Associati of Turin, Italy [18]

The last of three possible states of water is ice. Basically, to be more precise, the usage of the ice as a construction material is not purely recent invention: many northern people, such as Eskimos, having preserved their tradition of building igloos and units, often use ice caves for establishing their settlements. Today the techno-creation for ice may be demonstrated by creative mood of modern society to make their life more diverse. For this purpose they build ice hotels (since 1980), ice restaurants and bars, SPA centres, palaces of ice sculptures, etc.

During last decade Ice Hotels were opened in Sweden, Canada, Alaska (USA), Norway, Japan, Germany, Romania etc. Very often they provide additional après-ski facilities at some ski resorts, for example, in Andorra, Sweden, Norway, Canada, etc. Usually, ice hotels are temporary buildings made up of snow, sculpted blocks of ice, and, in some cases, some steel framing. Most of ice hotels are reconstructed every winter, and are dependent upon constant sub-freezing temperatures during construction and operation. The hotel is usually made (the architecture and size may vary from season to season) in arches of 16 feet $(5 \mathrm{~m})$ over rooms. The walls are over 4 feet $(1.2 \mathrm{~m})$ thick on average. All furniture is usually also made of ice: beds, chairs, counters, glasses and more.

Another popular type of ice-made attraction is ice bar Today you can "warm-up" in a cold atmosphere of ice bars in almost all major cities, such as London, New York and others. And you can visit them at any season. In Las Vegas, for example, sophisticated technology of maintaining the 
cold and new generation of insulating materials permitted to locate an ice bar in a middle of a desert - area with the 40 plus heat degree.

Beginning of the XXI century shows a steady development of the Ice Architecture Sector- appearance of new buildings and facilities, a constant increase in demand for this type of vacation. Strong competition in tourism lead to emerging of new exotic ice objects such as elements of spa centres, churches, chapels, museums, sculptures, etc. The range of ice architecture is constantly expanding and does not seem to stop. So, regarding relatively old, and, therefore, more traditional usage of ice and snow as a constructional material is distinctive to further develop and enhance new technical possibilities and introduce new insulation materials.

\section{Main Forms and Shapes of Water in Techno-Creation Usage}

Water has a great number of unique properties such as transparency and limpidity, fluidity or flow-ability, reflection and refraction, etc. Active utilisation of water's plastic features is the feature of the techno-creative design. The natural fickleness of water states gives today a strong aid to creative thinking of architects and creators.

Such particularity of natural water state as fluidity is being displayed by the usage of water's both static and dynamic forms for creation of unique aesthetical and spatial effects of the environment. It's possible to distinguish such shapes of the dynamic "architecture of water" as compression, flowing and falling down (pressure, stream and fall). Modern practice also widely utilises the reflecting feature of water mirror. Various aspects of utilising the dynamic water features for park and garden water implementations were investigated by specialists from many countries, for instance, John O. Simonds (1971) and A. Bahamon (2006) in the USA, Z. Nikolaevskaya (1989) in Russia, I.D. Rodichkin (1990) in Ukraine, etc.

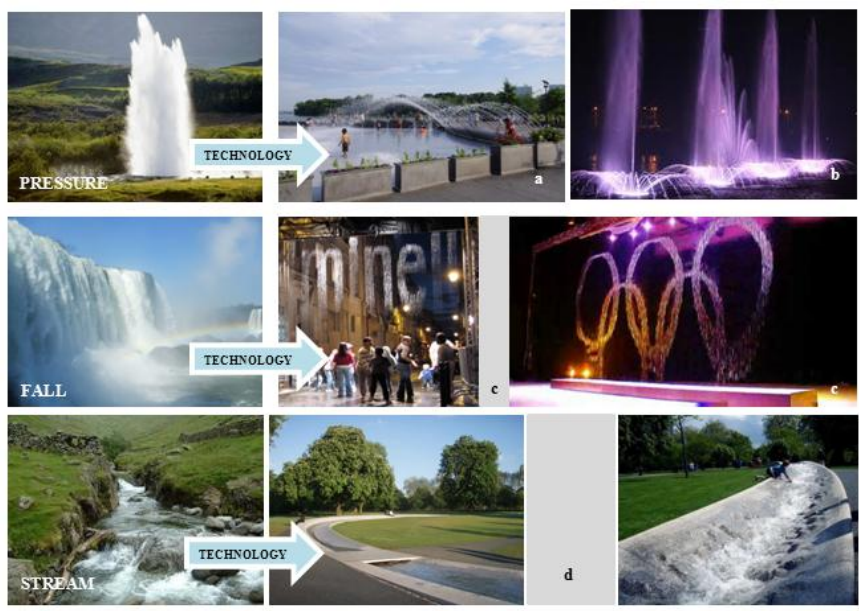

Figure 3. The Dynamic Forms of Water for Techno-Creation [7]. (a. The embankment of Potomack river, Georgetown, Washington DC, USA, 2011 (phot. L.Ruban); b. Multimedia fountain, Vinnitsa, Ukraine, 2011, (phot. L/Ruban); c. The AquaScript technology, Tokyo Bay Monsterfashion show, 2007. Julius Popp. (phot.J. Popp); d. The Diana, Princess of Wales Memorial Fountain, London, UK, 2003-2004 (phot. official site and L.Ruban))
The variety of water shapes defines the arsenal of corresponding hydro technical implementations. Dynamic water features are used in such hydro devices as fountains, cascades, water drops, rifts, waterfalls, etc. The 3D fountains featuring scenario "dance of spouts", fountains with multimedia facilities (e.g in Singapore, Dubai, UAE or Vinnitsa, Ukraine) have been recently emerged. Several technologies, such as AquacSript [19] or Digital Water Curtains [20] investigate the possibilities of using the water as a kind of informational carrier. Modern trends of the creative technology market prove that natural decorative features of the water hold a great potent for future technocreative usage.

\section{The PARAllel "Realities" of LANDSCAPING PRACTICE}

There is a great potential of complex research of modern possibilities of usage of water nowadays. It will be useful to the make the parallel investigation of other, not less interesting aspects of water creativity. The alternative trends of studying the water may help to receive the new results.

In fact, the idea to put in base of investigation the three possible physical states of water can be also spread into the other branches of the research.

\section{A. Water as the natural habitat environment}

For completeness of disclosure of a subject it's necessary to study three water states as habitat and design for mankind needs [8, 9. 12].

In XXI century the permafrost territories and glaciers became an attractive location place for setting there constructions which require natural subzero temperature conditions. Some companies establish their remote computer data centers where computers are cooled naturally without high power consuming cooling systems.

One of considerable events in the development of glaciers became a construction of a Global Seed Vault in Norway, 2008. It became a really distinguished construction as from architectural point of view as by its purpose.

The Svalbard Global Seed Vault (Norwegian: Svalbard globale frohvelv) is a secure seedbank located on the Norwegian island of Spitsbergen in the remote Arctic Svalbard archipelago, about only 1,300 kilometers (810 mi) away from the North Pole.

Spitsbergen was considered ideal due to its lack of tectonic activity and its permafrost, which will aid preservation. The storage is located in rocky subsoil, at a 120-meter depth, and at the height of $130 \mathrm{~m}$ above sea level, where temperature of $-18{ }^{\circ} \mathrm{C}$ is constantly maintained. Such location ensures that the site remains dry even if the icecaps start to melt. According to developers of the project, even in case of a flood, falling of a meteorite or nuclear winter, the bank will be able to keep viability of all samples of a collection. Locally mined coal provides power for refrigeration units that further cool the seeds to the internationally recommended standard $-18{ }^{\circ} \mathrm{C}\left(0{ }^{\circ} \mathrm{F}\right)$. Even if the equipment fails, at least several weeks will elapse before 
the temperature rises to the $-3{ }^{\circ} \mathrm{C}\left(27^{\circ} \mathrm{F}\right)$ of the surrounding sandstone bedrock.

Each country has own part in the storage. The variety and volume of seeds stored will depend on the number of countries participating - the facility has a capacity to conserve 4.5 million sorts of plants.

Svalbard Global Seed Vault ranked at No. 6 on Time's Best Inventions of 2008.

Life under the water have always excited admirers of creativity Jules Verne. At the beginning of XXI century it has became possible thanks to the developed complicated technical solutions and emergence of new composite materials. Many of them were applied at construction of the underwater hotel of a Poseidon Undersea Resorts chain at Fiji (2008). The project was to be the world's first permanent one-atmosphere seafloor structure.

24 undersea suites are accessible by an elevator that takes guests $40 \mathrm{ft}$. below the surface. Nearly 70 percent of these rooms will be wrapped in 4-inch-thick clear acrylic, providing guests with a more-than-panoramic view of the ocean around them, and guests can use an in-room control console to encourage marine life to their windows with external feeding and lighting options [21]. All guests can use a submarine or a special tunnel from the beach to get into the underwater restaurant, bar, a library, conference room, wedding chapel or spa. Poseidon was conceived and developed by L. Bruce Jones, president of U.S. Submarines, Inc.

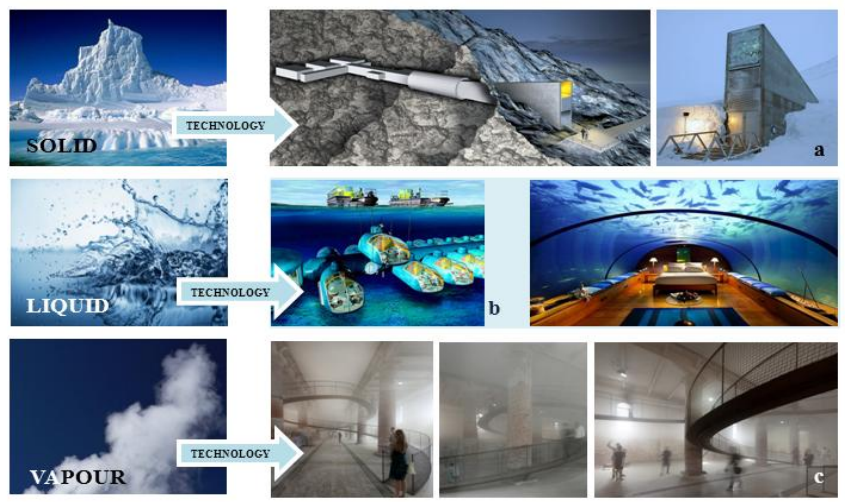

Figure 4. Water as the Habitat (a. the Global Seed Vault, Spitsbergen, Norway , 2007-2008, (by official side); b. underwater hotel The Poseidon Undersea Resorts, island Katafinga, Fiji, 2008 (by Poseidonresort.com); c. instalation Cloudscapes by Tetsuo Kondo Architects and environmental engineering firm Transsolar, Venice Architecture Biennale, 2010 ( by Tetsuo Kondo Architects))

The first underwater hotel, which was built in 1986, was Jules' Undersea Lodge located in Key Largo, Florida. However its guests had to scuba dive to get to their room at the deep of 21 feet $(6.4 \mathrm{~m})$ under water.

The fact of sustained usage of vapor in the architecture relates to the far future. For the present it is not so easy to make a long cast ahead. Today the painters and sculptors widely use the vapor like creative element for the artinstallation. That is why the new technology of man-made vapor has appeared. Creating clouds indoors is only possible through climate engineering, by applying physical principles at the building scale

The technology of skillfully creating clouds Nimbus inside indoor spaces based on controlling the weather conditions of a room. It is an act that requires meticulous planning entailing carefully controlling the temperature and humidity levels of the room, constantly moistening the air inside it and adjusting the lighting to create a dramatic and realistic effect. The Nimbus was created by Berndnaut Smilde - the artist from Holland in 2010-2012 [22].

Another example of similar technology is the creation of Cloudscapes by Tetsuo Kondo Architects and environmental engineering firm Transsolar. They have suspended a cloud inside the Arsenale exhibition space at the Venice Architecture Biennale 2010. The installation Cloudscapes was created by pumping three layers of air into the space: cold dry air at the bottom, hot humid air in the middle and hot dry air at the top. The installation forms part of the exhibition People Meet in Architecture, directed by Kazuyo Sejima of SANAA [23].

\section{B. Water Objects as the landscape planning basis}

Another approach could be shown up by the determination of the role of landscape water objects in modern architectural practice. The research studies in depth the fundamental principles of architectural and landscape theory and practice, which are dedicated to different water objects, their meaning and planning methods of organisation. But for the aim of this research some aspects of planning contemporary trends may be interesting as well.

According to the definition provided in Water Code of Ukraine, (1995), the Water Object is described as a natural or artificial object of landscape or geological structure, where the water can be collected [24]. The native properties of water, such as fluidity, help to form the variety of water objects in combination with other landscape shapes (relief, etc.).

Basically, all water objects may be divided into the two main groups:

- $\quad$ natural, such as lake, river and sea;

- $\quad$ artificial, which includes pond, canal and reservoir.

They are the landscape water objects that became the planning basis of territorial organisation [13]. Therefore, waterside territories of all water objects are currently in the focus of modern landscape practice.

The variety of landscape water objects may be connected to main hydrological characteristics of object, characteristics of other surrounded landscape components (relief, greenery, etc.), climate conditions, existing town planning context, etc.

Water objects play a significant role in the territories' compositional structure [13]. It is possible to distinguish several main categories of composition that are usually being used for characteristics of water objects in general landscape space-compositional structure. Water object may be enriched 
by planning solution to become a main, culminating, focus element of composition. It can play the role of spatial planning axe $[13,14]$ or be the background for architectural dominant or panoramic view.

The different factors that impact on water objects must be taking into account when they are treated as compositional planning element. It's connected with their characteristics such as geometry size, square of water mirror, configuration of general shape, placement in the surrounding landscape and so on. It is necessary to pay attention to the dynamic or static ways of existence of water, the influence and ties with relief, greenery, possible housing, etc.

The functions of landscape water object's territories can also be analysed from the point of view of three physical states of water. Since every climate zone and different region has its set of appropriate water objects and conditions, suitable for them. So, depending on specific climate conditions, not every water object can exist in vapour or solid state.

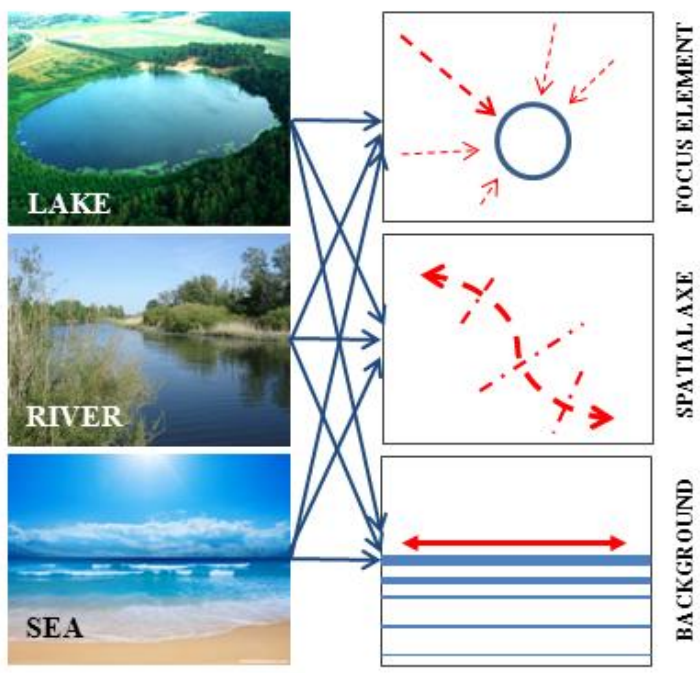

Figure 5. Water Objects in Landscape Planning Composition (by L.Ruban)

Most natural state of landscape water objects is water in its liquid state, with exception of arid landscapes or regions of permafrost. Therefore, main functions of water objects are recreational, water protecting, housing, therapeutic and attractive.

During winter seasons lakes or river valley sectors may get frozen. For this period main functions may be extended by additional sport and entertaining activities and all types of construction actions, mentioned in section III.B of this article.

The geysers and thermal wellsprings are the representatives of the most rarely occurred group, where water appears in vapour state. Their most typical functions are nature protective, therapeutic and recreational.
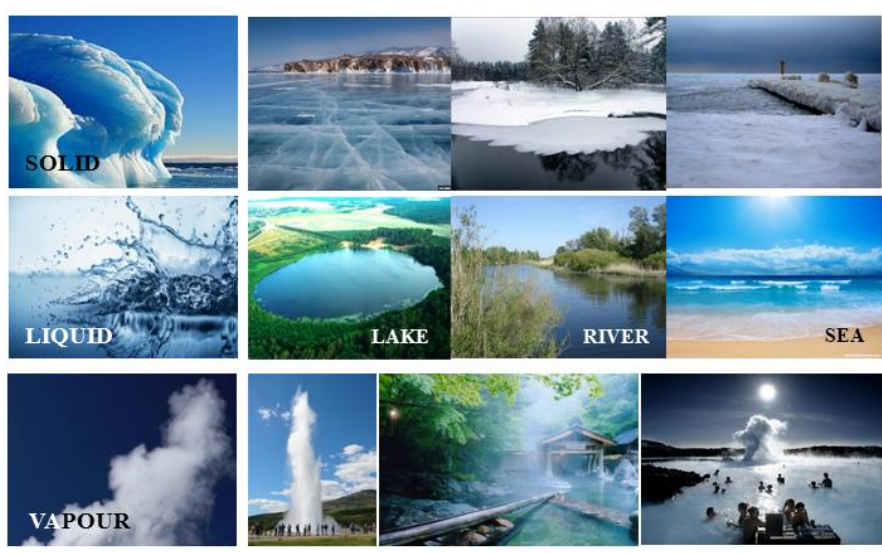

LANDSCAPE WATER OBJECTS

Figure 6. Landscape Water Objects and possible phisical states of water. (by L. Ruban)

It's worth mentioning that changes to the aggregate state of water result in changes of aesthetic perception of water objects and human's emotional environment. Thus, the spectacular view of frozen Niagara causes mixed emotions from surprise to rapture and admiration. But this area lies beyond the scope of our research.
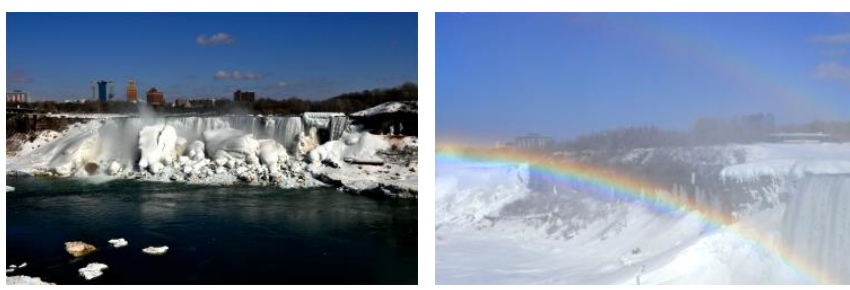

Figure 7. Canada, Niagara Waterfall is partly in ice, 2014, (photos by A.Voloschenko).

At the same time, changes in the aggregate states allow multi-functional utilisation of territories. In particular, vale of Svisloch River in Minsk, Belorussia, in winter is used by city population as ski tracks.

The analysis performed gives another possibility to evaluate the diversity of landscape water objects, to understand their attractiveness, estimate their value and to elaborate suitable methods of planning organisation, aimed at the preservation, maintenance and protection of these areas, uncovering their versatile potential.

The variations of water's theme could be endlessly varying, deeply useful and cognitively important for the development of sustainable landscaping, rational planning and protective measures $[13,15]$.

\section{CONCLUSIONS}

As recognizing techno-creative activities as one of the current trends in landscape architecture, it has been noted that it is characterized by polarized approach to the roles of developing technologies in the undertaken creative acts. It can be also a servitude function, firmly established in accordance with the use of technical novelties with "the spirit of the times" - after all, the landscape architecture profession is also engineering. It can be as well an exposition of a 
techno-form programming as a part of a composed space being the domain of an architect's activity or, in the worst case, an accentuated element of this space. It should be noted that although the techno-creation is not a new approach in architecture, its dissemination and recently observed intensification and certainly its implantation on the grounds of landscaping authorizes us to attach it to the list of contemporary alternative architectural trends.

For some people, the landscape and the work within should be created in accordance to the idea of harmonious creation. There are compositions which surprise us with their scale and degree of technicisation but still maintain aesthetical restraint, even in untypical elegance or expressive solutions. For others, as a consequence of techno-creative changes, the only right way is the desire to seek novelty and originality without worrying about the lack of understanding by the recipient. It is worth noting that the experiment, as a phenomenon, is widespread and commonplace. It is increasingly more and more difficult to intrigue, move, or appal the recipient. The work of many contemporary artists is experimenting with form, space, material, technique and technology.

In each epoch, construction is determined by the technical conditions. Thus, attention should be paid to the pursuit of experimental use of various technological developments in newly landscaped surroundings. Showing different ways of creative activities certain technical means were identified which enable the implementation of the intended effects of the project.

Natural component of landscape architecture water was chosen like an example for techno-creative possibilities. The first decade of the new century is characterized by a technological shift, when even water turned from decorative element into construction material. By analysing the modern European buildings and objects of landscape architecture the new approaches to usage of "water" like primary construction material in contemporary architectural practice have emerged. For these purposes water can be used in all its three states of matter, as it was shown by some recent constructional projects. Water was used for making walls, roofs, vaporized water shell. Today most digital technologies worked out to show its potential in creating of dynamically transformable spaces. There is a trend for uniting and combination of several technologies together at the same time. But regarding the water in solid state - it is a phase of further technological improvement and aesthetic development. Freezing technology and maintaining low temperatures, as well as the emerging of new insulating materials contribute to further spread of ice constructions.

From Techno-creative point of view main shapes and forms of water were determined. The usage of water's static and dynamic forms for creation of unique aesthetical and spatial effects of the environment gives today a strong aid to creative thinking of architects and creators.

The three possible physical states of water were put as keystone of further researches. With this approach the water as a habitat and some aspects of landscapes water objects were investigated. As a habitant we have elaborated the new areas such as permafrost, underwater spaces used for human's needs. The utilization of these, previously undiscovered territories, became possible due to appearance of new technologies and progress in engineering. Since the landscape water objects are based on fundamental principles of classical theory and practices, the new trends lie in the direction of forward sustainable landscaping and nature protection steps. The analyses of spatial-compositional possibilities and priorities of functional usage of landscape water objects can help in definition of new trends for enriching the methods of sustainable landscaping.

Water landscapes are quite topical in modern landscape practice. Today the landscape architectural practice is one of the most actively changeable and extremely progressive areas of design. There is a great potential of complex research of modern possibilities of usage of water landscapes nowadays. It must be useful to the make the parallel investigation of other, not less interesting aspects of water creativity. The alternative trends of studying the water must help to receive the new results.

Techno-creative thinking about spatial design opens up new previously unavailable creative areas and allows for the execution of plans previously recognized as utopian. The technological revolution taking place before our eyes materializes in fascinating shapes and spatial layouts. The result of these processes is the formation of new aesthetic canons in contemporarily shaped landscapes, as if to confirm the words of Aristotle that "the arts either complement Nature with what she is unable to do, or imitate her in what she has done".

\section{ACKNOWLEDGMENT}

Authors express their gratitude to Global Science \& Technology Forum and Program Committee of $2^{\text {nd }}$ Annual International Conference on Architecture and Civil Engineering (ACE 2014) for providing excellent opportunity to participate in such high level forum and present results of their scientific research. Authors also want to thank for presenting them with Best Paper Awards ACE 2014 for the paper Water as the Factor of Techno-Creation and inviting them to publish at Journal Engineering Technology.

\section{REFERENCES}

[1] This publication is a presentation of some of the research results included in: S. Kuc, Techno-kreacja a architektura Krajobrazu. Wybrane zagadnienia (Techno-Creation in Landscape Architecture. Selected Issues.), Monograph 392, Cracow University of Technology Press, Krakow 2011, being the basis for the author's postdoctoral programme; some aspects of techno-creation was presented at Eurasian Multidisciplinary Forum, EMF, Tbilisi, 24-26.11.2013: some aspect of water architecture was presented at $1^{\text {st }}$ World Milti_Conference on Intelligent Building Technologies \& Multimedia Management, $10^{\text {th }}$ International Conference New Building Technologies and Architectural Design, NBTAD 2013, Krakow, 2013 and some aspects of both of them was presented at $2^{\text {nd }}$ Annual International Conference on Architecture and Civil Engineering, ACE 2014, , Singapur, 24-25.03.2014 (S.Kuc, L.Ruban, "Water as the factor of techno-creation" was awarded: Best Paper Awards ACE 2014). 
[2] S. Kuc, Techno-kreacja a architektura krajobrazu. Wybrane zagadnienia (Techno-Creation in Landscape Architecture. Selected Issues.),, Monograph 392, Cracow University of Technology Press, Krakow 2011, p. 186.

[3] S. Kuc, "Techno-kreacja w architekturze krajobrazu," International Congress of Polish Landscape Architects, The Art of Protecting and Shaping the Environment. Profession - Theory - Education, 2022.09.2007, Krakow, Technical Transactions, CUT, vol. 5-A/2007, No. 10 (year 104), pp. 215-217.

[4] S. Kuc, "Techno-kreacja w architekturze krajobrazu," conference materials, $6^{\text {th }}$ International Scientific and Technical Conference: Design Problems in the Context of New Building Technologies, scientific ed. Jan Kurek, D.Sc. Ph.D. Arch., Sabina Kuc, Ph.D. Arch., PAS Krakow and CUT Faculty of Architecture, Krakow, 2005, Technical Transactions, vol. 6-A/2005, pp. 43-48.

[5] S. Kuc, Sabina Kuc, "Techno-creation as a unique part of landscape architecture,” Eurasian Multidisciplinary Forum, 24-26.10.2013, Tbilisi, in press.

[6] The Metapolis Dictionary of Advanced Architecture. City, Technology and Society in the Information Age, ed. S. Cros, Barcelona, 2003.

[7] S. Kuc, L. Ruban, "Water as the factor of techno-creation," Proceedings of a $2^{\text {nd }}$ Annual International Conference of Architecture and Civil Engineering (ACE-2014), ISSN: 2301-394X, published and organized by Global Science and Technology Forum (GSTF), 2014, Singapore, pp. 50-54. (Best Paper Awards ACE 2014).

[8] L. Ruban, "Recent trends in the use of water in modern architecture: new approaches to space modeling," $1^{\text {st }}$ World Milti_Conference on Intelligent Building Technologies \& Multimedia Management, $10^{\text {th }}$ International Conference New Building Technologies and Architectural Design, NBTAD 2013, Krakow, 2013, Abstracts, p.86.

[9] L. Ruban, "Three states of water: how technology makes water a construction material," Czasopismo Techniczne, Politechnika Krakowska, 2014, in press.

[10] Paul Cooper, New Tech Garden, Mitchell Beazley London, 2002.

[11] P. Jodidio, Architecture Now, vol.2, Taschen, 2001.

[12] L. Ruban, "Modern trends in the usage of water in contemporary architectural-landscape practice," The new Ideas of New Century 2014 : The Fourteenth International Scientific Conference Proceedings : in 3 vol. / Pacific Ocean state university - Habarovsk: Ed. Pacific Ocean State University, 2014. - 3 vol. ISBN 978-5-73891394-5, V. 3. - 441 p. ISBN 978-5-7389-1397-6, V. 3, pp. 160-166 (russian)

[13] L. Ruban, The Architectural-Landscape Organization of Streamside Territories: the tutorial / edited by prof. Panchenko T.F., Kiev, KNUCA, 2013. - $92 \mathrm{p}$.

[14] L. Ruban, "Value determination of water systems in historic gardens as the foundation of garden art work," XX anniversary conference "Contemporary status of historic gardens (value determination of garden art works and their preservation)," Instytut Architektury Krajobrazu Politechniki Krakowskiej im. Tadeusza Kościuszki, Krakow, 14-16.11. 2013, in press.

[15] L. Ruban, "Water systems of historical gardens, principal structure issues," Contemporary Challenges of Architecture and Townplanning, Kiev, KNUCA, 2012, Issue 31, pp. 169-179.

\section{INTERNET SOURCES}

[16] http://www.designboom.com/eng/funclub/dillerscofidio.html, Viewed 01.05.2014.

[17] http://www.arcspace.com/features/diller--scofidio--renfro/blurbuilding/, Viewed 01.05.2014.

[18] http://www.carloratti.com/project/digital-water-pavillion/, Viewed 01.05.2014.

[19] http://www.technovelgy.com/ct/Science-FictionNews.asp?NewsNum=1435, Viewed 01.05.2014.

[20] http://www.digitalwatercurtain.com, Viewed 01.05.2014.

[21] http://www.recommend.com/themes/active/sleep-fishes-poseidonresorts/, Viewed 01.05.2014.

[22] http://www.yatzer.com/nimbus-berndnaut-smildel, 01.05.2014.

[23] Cloudscapes by Tetsuo Kondo Architects and Transsolar, 2010, September, 6 // http://www.dezeen.com/2010/09/06/cloudscapes-bytetsuo-kondo-architects-and-transsolar/, Viewed 01.05.2014.

[24] Water Code of Ukraine: adopted 06.06.1995 № 213/95 - VR// Records of Verkhovna Rada of Ukraine, 1995, № 24, parag.2,3, Viewed 01.05.2014.

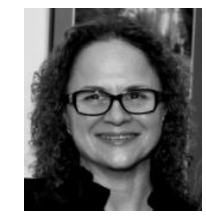

Sabina Kuc architect, Krakow, Poland. Ph.D. degree in architecture in 1997 and the Ph.D.D.Sc. degree in landscape architecture in 2012 from the Faculty of Architecture, Cracow University of Technology, Krakow, Poland.

In 1986 she joined CUT as an Assistant, became an Assis.Professor in 1987 and an Assoc.Professor in 2012. She was the Visiting Professor at ENU (Astana, Kazahstan, 2013).

Current research interests: techno-creation, construction and building technologies in landscape architecture and landscape water objects.

Asoc.Prof. S.Kuc is a member of APA in 1987, SBT at the Krakow Branch of the PAS in 1994, and RCA in 2002. Diploma "Best Research Paper", ACE-2014, Singapore (with Ph.D.L.Ruban, Ukraine).

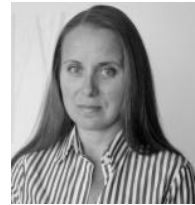

Luidmila Ruban, architect, Kiev, Ukraine. Diploma in major "Architecture", KCEI, Kiev, Ukraine, 1992. Ph.D. Diploma in "Town planning and landscape architecture", KNUCA, Kiev, Ukraine, 2000. The Diploma of Associate Professor, KNUCA, Kiev, Ukraine, 2013.

She works as lecturer of Landscape Architecture Department, Faculty of Architecture, KNUCA, Kiev, Ukraine. The main publications are: The Principles of Town-Planning Use of Territories under Degraded River's Conditions (Ukraine: KNUCA, 2000); The Architectural-Landscape Organization of Streamside Territories (Ukraine: KNUCA, 2013).

Asoc. Prof. L. Ruban is a member of NUAU, UA, 2012; a member of RHS, UK, 2006. Diploma "Best Research Paper", ACE-2014, Singapore (with Ph.D.D.Sc. S.Kuc, Poland). 